\title{
DESEMPENHO DO ELETRODO DE FILME DE PALÁDIO NA DETERMINAÇÃO DE TÁLIO E CHUMBO EM AMOSTRAS DE ÁGUAS NATURAIS POR VOLTAMETRIA DE REDISSOLUÇÃ̃ ANÓDICA COM PULSO DIFERENCIAL
}

\author{
Jorge Luís O. Santos ${ }^{a}$, Oldair D. Leite ${ }^{\mathrm{b}, *}$, Clayton Ricardo Janonic, Djane S. de Jesus ${ }^{\mathrm{d}}$ e Ana Maria P. dos Santos \\ ${ }^{a}$ Centro Multidisciplinar de Bom Jesus da Lapa, Universidade Federal do Oeste da Bahia, 47600-000 Bom Jesus da Lapa - BA, Brasil \\ 'Departamento de Química, Universidade Tecnológica Federal do Paraná, 85884-000 Medianeira - PR, Brasil \\ ${ }^{\circ}$ Centro das Ciências Exatas e das Tecnologias, Universidade Federal do Oeste da Bahia, 47800-000 Barreiras - BA, Brasil \\ 'Instituto Federal de Educação, Ciência e Tecnologia da Bahia, 40110-150 Salvador - BA, Brasil \\ eInstituto de Química, Universidade Federal da Bahia, 40170-115 Salvador - BA, Brasil
}

Recebido em 09/02/2017; aceito em 09/05/2017; publicado na web em 19/07/2017

\begin{abstract}
PERFORMANCE OF A PALLADIUM FILM ELECTRODE FOR THE DETERMINATION OF THALLIUM AND LEAD IN NATURAL WATER SAMPLE BY DIFFERENTIAL PULSE ANODIC STRIPPING VOLTAMMETRY. The use of a palladium film electrode (PdFE) as an alternative electrode for the determination of thallium $\left(\mathrm{Tl}^{+}\right)$and lead $\left(\mathrm{Pb}^{2+}\right)$ in water samples by anodic stripping voltammetry is proposed. Preliminary studies of the influence of the substrate were performed on the electrochemical behavior of PdFE prepared ex situ. Using a silver solid amalgam electrode as substrate (AgSAE), the effect of several parameters such as potential and deposition time, composition and $\mathrm{pH}$ of supporting electrolyte on the analytical response of $\mathrm{PdFE}$ for $\mathrm{Tl}^{+}$by differential pulse anodic stripping voltammetry (DPASV) was initially investigated. Under best experimental conditions of deposition potential of $-1.2 \mathrm{~V}$ and deposition time of $300 \mathrm{~s}$ the analytical curve was linear in the $\mathrm{Tl}^{+}$concentration from 3.0 to $100.0 \mu \mathrm{g} \mathrm{L}^{-1}$ with a relative standard deviation (RSD) $<2.0 \%$. The limit of detection (LOD) and limit of quantification (LOQ) were $0.89 \mu \mathrm{g} \mathrm{L}^{-1}$ and $2.96 \mu \mathrm{g} \mathrm{L}{ }^{-1}$, respectively. The PdFE was successfully applied for the determination of $\mathrm{Tl}^{+}$in water samples. Moreover, this electrode showed promising as a sensor for the simultaneous determination of $\mathrm{Tl}^{+}$and $\mathrm{Pb}^{2+}$ and as a suitable alternative to the mercury electrode.
\end{abstract}

Keywords: palladium film electrode; silver solid amalgam electrode; $\mathrm{Tl}^{+}$and $\mathrm{Pb}^{2+}$; differential pulse anodic stripping voltammetry (DPASV).

\section{INTRODUÇÃO}

O tálio é um metal raro com concentração na crosta terrestre na ordem de 0,1-1,7 $\mathrm{mg} \mathrm{kg}^{-1}$, estando presente nos minérios de sulfeto de zinco, cobre, chumbo e também em carvão. Por conta de sua densidade $\left(11,83 \mathrm{~g} / \mathrm{cm}^{3}\right)$, é classificado como um metal pesado. ${ }^{1}$ Existem poucas jazidas de tálio no mundo, estando localizadas na China, Cazaquistão e mais recentemente no Brasil. ${ }^{2,3}$ Descoberta em 2011, a jazida de tálio brasileira está localizada no município de Barreiras, Oeste da Bahia, e possui um potencial de produção estimado em aproximadamente 60 toneladas. $^{4}$

Apesar de possuir importantes aplicações tecnológicas, ${ }^{1,5}$ os efeitos tóxicos do tálio são notadamente conhecidos, sendo mais prejudicial à saúde humana do que o mercúrio, chumbo, cobre e zinco. ${ }^{1}$ Em função da toxidez do tálio muitos métodos analíticos foram desenvolvidos a fim de monitorar os níveis desse metal em diversas matrizes, tais como águas naturais, ${ }^{6}$ solos ${ }^{7}$ e amostras biológicas. ${ }^{8}$ Entre as técnicas analíticas utilizadas na determinação de tálio, destacam-se a espectrometria de absorção atômica (AAS, Atomic Absorption Spectrometry), a espectrometria de emissão atômica com plasma acoplado indutivamente (ICP-AES, Inductively Coupled Plasma - Atomic Emission Spectrometry), espectrometria de massas com plasma acoplado indutivamente (ICP-MS, de Inductively coupled plasma mass spectrometry) e a voltametria de redissolução anódica. ${ }^{9,10}$

A voltametria de redissolução anódica é considerada uma das ferramentas mais poderosas na determinação de elementos em nível de traço e ultra traço de metais pesados. ${ }^{11-13} \mathrm{~A}$ alta sensibilidade da voltametria de redissolução anódica é atribuída a associação de uma

*e-mail: oldair.leite@gmail.com etapa de pré-concentração do analito, na superfície do eletrodo de trabalho, com a etapa da medida do sinal analítico na redissolução do analito. Porém, o desempenho das técnicas voltamétricas está relacionado, além de outros parâmetros, sobretudo à escolha adequada do eletrodo de trabalho. ${ }^{14}$

Os eletrodos de mercúrio (e.g. eletrodo de mercúrio gotejante (DME, Dropping Mercury Electrode) e eletrodo de filmes de mercúrio (MFE, Mercury Film Electrode) foram os mais extensivamente empregados na determinação de metais pesados por voltametria de redissolução anódica. ${ }^{14}$ As principais vantagens do uso dos eletrodos de mercúrio são: possibilidade de renovação da sua superfície, no caso do DME, facilidade do mercúrio em formar amálgamas com os metais, além de uma ampla faixa de trabalho na região catódica. ${ }^{14,15}$

Porém, devido à toxicidade do mercúrio, eletrodos de filme de bismuto (BiFE, Bismuth Film Electrode) ${ }^{16-18}$ têm sido empregados como alternativa promissora aos eletrodos de mercúrio. As propriedades dos BiFEs em análises voltamétricas são comparáveis às atribuídas aos MFEs, isto porque o sobrepotencial de redução do hidrogênio no bismuto também é muito negativo e forma com os metais pesados ligas análogas aos amálgamas formadas com o mercúrio. ${ }^{19}$ Entretanto, o limite catódico do BiFE é bastante dependente do pH da solução, apresentando um maior intervalo catódico em soluções alcalinas e grandes limitações quando utilizados em soluções ácidas. ${ }^{19}$ Dependendo da acidez do meio e do potencial de redução do analito, fica restritivo o uso de BiFE na determinação de alguns metais pesados.

Mais recentemente, tem sido reportado na literatura o uso de eletrodos de filme de antimônio (SbFE, Antimony Film Electrode) e eletrodos de filme de estanho (SnFE, Tin Film Electrode) na determinação de metais pesados, em substituição aos MFEs. ${ }^{20-22}$ Os SbFEs 
demonstraram um desempenho analítico semelhante aos BiFEs, porém, em comparação, possuem a vantagem de serem utilizados em meios fortemente ácidos $(\mathrm{pH}<2)$ além de apresentarem uma janela útil de potencial mais ampla. ${ }^{23,24}$

O paládio é um metal com alta atividade catalítica, não é tóxico e possui propriedades eletroquímicas parecidas com a da platina. ${ }^{15,25}$ São poucas as aplicações dos eletrodos de paládio em trabalhos eletroanalíticos, sendo mais extensivamente utilizados em processos eletrocatalíticos. Essa limitação se deve, muito provavelmente, à presença de correntes de absorção, adsorção e dessorção de hidrogênio em potenciais anódicos, ao baixo valor do sobrepotencial de redução do hidrogênio em potenciais catódicos e à alta taxa de desprendimento de hidrogênio gasoso na superfície do eletrodo, fatores que podem interferir no sinal analítico. ${ }^{26}$ Entretanto, têm sido reportado em alguns trabalhos o uso de eletrodos de paládio na determinação de algumas espécies orgânicas ${ }^{27-29} \mathrm{e}$ inorgânicas. ${ }^{30,31}$

Até o presente, não há reportado na literatura, o emprego de eletrodo de filme de paládio para a determinação de metais pesados. Relata-se, porém, que os íons de metais pesados possuem uma grande capacidade de alterar a atividade catalítica do paládio. ${ }^{32} \mathrm{O}$ mecanismo de envenenamento ou promoção catalítica do paládio por íons de metais pesados ainda não é muito bem conhecido. ${ }^{32}$ Contudo, alguns autores supõem que a inibição catalítica ocorre porque esses íons formam ligações muito fortes com o paládio, sugerindo que os íons dos metais pesados (e.g. $\mathrm{Pb}^{2+}, \mathrm{Cd}^{2+}, \mathrm{Tl}^{+}, \mathrm{Cu}^{2+}$ e $\mathrm{Hg}^{2+}$ ) são descarregados na superfície do paládio e são depositados na forma metálica. ${ }^{33,34}$ Nesse caso, o catalisador de paládio se comporta como eletrodo e os íons dos metais pesados são depositados reversivelmente em sua superfície pelo fenômeno de deposição em regime de subpotencial. ${ }^{32}$

Neste trabalho foi avaliado o desempenho do eletrodo de filme de paládio (PdFE) na determinação de $\mathrm{Tl}^{+}$por voltametria de redissolução anódica com pulso diferencial. Uma vez que a literatura traz a possibilidade da ocorrência de tálio associado ao minério de chumbo, ${ }^{35}$ também foram realizadas a determinação simultânea de $\mathrm{Tl}^{+}$e $\mathrm{Pb}^{2+}$. Ademais, as amostras de água do rio analisadas foram coletadas a jusante da jazida de tálio, próximo à área urbana de Barreiras - BA, visando avaliar a presença e/ou contaminação com estes elementos.

\section{PARTE EXPERIMENTAL}

\section{Reagentes e soluções}

Todas as soluções utilizadas neste trabalho foram preparadas empregando reagentes de qualidade analítica e utilizando água ultra pura, obtida de um sistema de purificação de água Mill-Q, modelo Direct- $Q{ }^{\circledR}$ da Merck MilliPore.

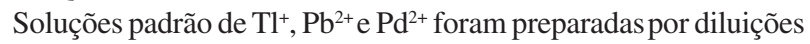
das soluções padrão de $1000 \mathrm{mg} \mathrm{L}^{-1}$ (Atomic Absorption Spectroscopy, Merck). As soluções de 1,0 mmol L-1 de $\mathrm{H}_{2} \mathrm{SO}_{4}, 1,0 \mathrm{mmol} \mathrm{L} \mathrm{L}^{-1}$ de $\mathrm{HCL}, 1,0 \mathrm{mmol} \mathrm{mol} \mathrm{L}{ }^{-1}$ de $\mathrm{HNO}_{3}, 0,1 \mathrm{~mol} \mathrm{~L}^{-1} \mathrm{de} \mathrm{K}_{2} \mathrm{SO}_{4}, 0,1 \mathrm{~mol} \mathrm{~L}{ }^{-1}$ de $\mathrm{KCl}$ e $0,1 \mathrm{~mol} \mathrm{~L}^{-1}$ de $\mathrm{KNO}_{3}$ foram preparadas e avaliadas como eletrólito de suporte.

\section{Instrumentação}

As medidas eletroquímicas foram realizadas em um potenciostato/galvanostato portátil modelo $\mu$ STAT 400 da DropSens acoplado a um computador portátil gerenciado pelo software DropView 2.9, utilizando uma célula eletroquímica convencional de 3 eletrodos, com capacidade de $25 \mathrm{~mL}$. Foi empregado como eletrodo de referência o eletrodo de $\mathrm{Ag} / \mathrm{AgCl}\left(\mathrm{KCl} 3 \mathrm{~mol} \mathrm{~L}^{-1}\right)$, o eletrodo auxiliar foi de aço inoxidável e o eletrodo de trabalho foi o filme de paládio depositado em eletrodo sólido de amálgama de prata (AgSAE, Ag solid amalgam electrode). Também foram avaliados como eletrodos de trabalho o filme de paládio depositado na superfície do eletrodo de pasta de carbono (CPE) e do eletrodo de carbono vítreo (GCE).

As aquisições das imagens topográficas do filme de paládio foram realizadas no Laboratório de Microscopia Eletrônica (LAMUME) do Instituto de Física da Universidade Federal da Bahia (UFBA), utilizando-se um Microscópio de Força Atômica modelo SPM 9700 da Shimadzu. Na obtenção das imagens foi realizada varredura na superfície do filme, numa área de $5 \mu \mathrm{m}$ x $5 \mu \mathrm{m}$, com o equipamento operando no modo de não contato. Os resultados da composição química do filme de paládio e as micrografias da superfície do filme foram obtidas utilizando um Microscópio Eletrônico de Varredura acoplado à Espectrômetro de Energia Dispersiva, modelo Quanta 250 (FEI Company), instalado no Centro de Microscopia Eletrônica da Universidade Estadual de Santa Cruz (UESC).

\section{Preparo do substrato, eletrodo de amálgama de prata (AgSAE) e do filme de paládio}

O eletrodo de filme de paládio foi obtido pela deposição eletroquímica do paládio na superfície do AgSAE. O AgSAE na proporção em massa 33,3/66,6 (Ag/Hg, m/m) foi preparado pela homogeneização de 0,5 g de prata metálica em pó (2-3.5 $\mu \mathrm{m})$ (Sigma-Aldrich) com $1,0 \mathrm{~g}$ de mercúrio P.A. (Vetec) em almofariz de ágata com pistilo. A pasta da amálgama de prata foi inserida em seringa hipodérmica de 1,00 mL e compactada com auxílio de um pistão metálico. O contato elétrico foi estabelecido com fio rígido de cobre com secção de 1,5 $\mathrm{mm}$. Depois, o eletrodo foi deixado em repouso por 24 horas para a cura (endurecimento) da amálgama. A superfície do AgSAE foi polida com lixa 1600 e depois com sucessivas fricções da superfície em papel sulfite A4 $75 \mathrm{~g} / \mathrm{m}^{2}$. Depois do polimento a superfície do AgSAE foi lavada com água ultrapura.

O filme de paládio foi depositado de dois modos diferentes: um foi a deposição in situ, na qual o paládio é adicionado na solução a ser analisada e é depositado na superfície do eletrodo junto com o analito de interesse; a outra forma foi por deposição ex situ, na qual o paládio é depositado em uma solução a parte (solução de deposição) antes do eletrodo ser aplicado na solução a ser analisada.

$\mathrm{Na}$ deposição in situ adicionou-se, na solução de análise, $\mathrm{Pd}^{2+}$ na concentração 4,0 $\mathrm{mg} \mathrm{L}^{-1}$, sendo a deposição realizada através da aplicação de um potencial constante de $-1,2 \mathrm{~V}$ durante o tempo de 300 s. No caso da deposição ex situ, preparou-se uma solução de deposição contendo $20 \mathrm{mg} \mathrm{L}^{-1}$ de $\mathrm{Pd}^{2+}$ em 1,0 mmol L-1 de $\mathrm{H}_{2} \mathrm{SO}_{4}$. Na deposição ex situ do filme de paládio, para garantir a formação de um filme homogêneo do negro de paládio (partículas finamente divididas), foi aplicado um potencial de $-1,2 \mathrm{~V}$ durante $300 \mathrm{~s}$. Neste processo, a fim de minimizar a influência do hidrogênio na homogeneidade do filme de paládio, a solução foi agitada vigorosamente com agitador magnético.

A fim de verificar se o valor do sobrepotencial de redução do hidrogênio no filme de paládio sofre influência do substrato, também foram preparados filme de paládio depositados nos eletrodos de carbono vítreo (GCE) e nos eletrodos de pasta de carbono (CPE).

\section{Procedimento}

Os estudos do comportamento eletroquímico do eletrodo de filme de paládio foram realizados em solução aquosa do eletrólito suporte contendo os analitos de interesse e na presença de oxigênio atmosférico dissolvido. Durante a etapa de pré-concentração, as soluções foram saturadas com oxigênio pela agitação por 5 minutos 
em agitador magnético, e com o auxilio de um oxímetro foram verificados teores de oxigênio próximos de $2,9 \mathrm{mg} \mathrm{L}^{-1}$. As medidas eletroquímicas foram realizadas empregando as técnicas de voltametria de redissolução anódica com pulso diferencial (DPASV, Differential Pulse Anodic Stripping Voltammetry) e a voltametria cíclica (CV, cyclic Voltammetry).

O comportamento eletroquímico do filme de paládio foi estudado empregando a técnica de voltametria cíclica, realizando primeiro uma varredura anódica entre os potenciais $-2,0 \mathrm{~V}$ a $+0,4 \mathrm{~V}$ e depois uma varredura catódica entre os potenciais $+0,4 \mathrm{~V}$ a $-2,0 \mathrm{~V}$.

Estudos de otimização com o filme de paládio foram realizados ${ }^{36}$ utilizando a técnica de DPASV. Empregaram-se neste trabalho as melhores condições operacionais, que foram: na etapa de deposição e pré-concentração usou-se um potencial de -1,2 V, tempo de deposição de 300 s e tempo de equilíbrio 20 s; na etapa de redissolução e medida da corrente a varredura foi feita no sentido anódico, na faixa de potencial de $-1,2 \mathrm{~V}$ a $-0,2 \mathrm{~V}$, com velocidade de varredura de 80 $\mathrm{mV} \mathrm{s}^{-1}$, amplitude de pulso de $50 \mathrm{mV}$ e tempo de pulso de $10 \mathrm{~ms}$; na etapa de condicionamento e "limpeza" do eletrodo aplicou-se um potencial de $0,2 \mathrm{~V}$ durante $30 \mathrm{~s}$.

Empregando as condições operacionais otimizadas para o $\mathrm{Tl}^{+}$, foi avaliada a determinação simultânea do elemento $\mathrm{Pb}^{2+}$, nas amostras de água de rio, pela técnica de DPASV no intervalo entre 5,0 a $80,0 \mu \mathrm{g} \mathrm{L}^{-1}$.

\section{Amostragem}

As amostras de água foram coletadas em três pontos (A1, A2 e A3) no Rio de Ondas, na cidade de Barreiras - BA, ao longo do trecho entre a reserva de tálio $\left(12^{\circ} 8^{\prime} 49.61^{\prime \prime} \mathrm{S}\right.$ e $\left.45^{\circ} 8^{\prime} 19.58^{\prime \prime} \mathrm{O}\right)$ e antes do encontro com o Rio Grande. As amostras de água, coletadas em frascos de polietileno previamente lavados com solução de $10 \%$ v/v de $\mathrm{HNO}_{3}$ P.A (Merck) e água ultrapura, foram transportadas ao laboratório sob refrigeração a aproximadamente $4{ }^{\circ} \mathrm{C}$ e analisadas no mesmo dia da coleta.

\section{RESULTADOS E DISCUSSÃO}

\section{Influência do substrato na resposta do eletrodo de filme de paládio e no sobrepotencial de redução do hidrogênio}

As propriedades do substrato exercem influência não somente na sensibilidade do filme metálico, bem como, no valor do sobrepotencial de redução do hidrogênio. ${ }^{37}$ Como o paládio apresenta um baixo valor para o sobrepotencial de redução de hidrogênio, inicialmente foi estudada a influência do tipo de substrato no valor do sobrepotencial. Nesse estudo foram utilizados como substrato os eletrodos de pasta de carbono (CPE), eletrodo de carbono vítreo (GCE) e eletrodo sólido de amálgama de prata (AgSAE).

Nas condições experimentais utilizadas nesse trabalho, os filmes de paládio depositados tanto no CPE quanto no GCE apresentaram em soluções eletrolíticas de $0,1 \mathrm{~mol} \mathrm{~L}^{-1}$ de $\mathrm{K}_{2} \mathrm{SO}_{4}$ e $1,0 \mathrm{mmol} \mathrm{L}^{-1} \mathrm{de}$ $\mathrm{H}_{2} \mathrm{SO}_{4}$ valores de sobrepotencial de redução de hidrogênio muito baixo e uma grande produção de hidrogênio na superfície do eletrodo, inviabilizando assim, para os propósitos desse trabalho, a utilização do filme de paládio nesses substratos.

O filme de paládio depositado no AgSAE apresentou valores de sobrepotencial de redução do hidrogênio adequados para o uso desse eletrodo na região catódica. No eletrólito ácido $\left(1,0 \mathrm{mmol} \mathrm{L}^{-1} \mathrm{H}_{2} \mathrm{SO} 4\right)$ houve a formação de hidrogênio gasoso somente em potenciais mais negativos que $-1,2 \mathrm{~V}$ e no eletrólito salino $\left(0,1 \mathrm{~mol} \mathrm{~L}^{-1} \mathrm{~K}_{2} \mathrm{SO}_{4}\right) \mathrm{em}$ potenciais mais negativos que -1,5 V. Esses valores podem ser atribuídos à influência do substrato no filme de paládio e, possivelmente, ao fato de a amálgama de prata possuir um valor de sobrepotencial de redução de hidrogênio alto e similar aos demonstrados pelos eletrodos de mercúrio. ${ }^{38,39}$ Portanto, no prosseguimento deste trabalho, foi empregado um filme de paládio depositado na superfície do AgSAE como eletrodo de trabalho.

Na Figura 1 são apresentados os voltamogramas cíclicos obtidos com o AgSAE e com o eletrodo sólido de amálgama de prata modificado com filme de paládio (PdF-AgSAE) em solução de $\mathrm{K}_{2} \mathrm{SO}_{4} 0,1$ mol L ${ }^{-1}$. O eletrodo sem o filme de paládio mostrou um intervalo de potencial útil entre $-1,7 \mathrm{~V}$ a $+0,2 \mathrm{~V}$ similar ao relatado na literatura para esse tipo de elétrodo, ${ }^{40}$ enquanto que o eletrodo com o filme de paládio apresentou intervalo mais estreito entre $-1,5 \mathrm{~V}$ a $-0,1 \mathrm{~V}$. A corrente de pico catódico observada no potencial de $0,0 \mathrm{~V}$, possivelmente, está relacionada com o processo de adsorção e absorção de $\mathrm{H}^{+}$. Já a corrente de pico anódico no potencial de $0,1 \mathrm{~V}$ está relacionada com a dessorção de $\mathrm{H}^{+}$. ${ }^{41-44}$

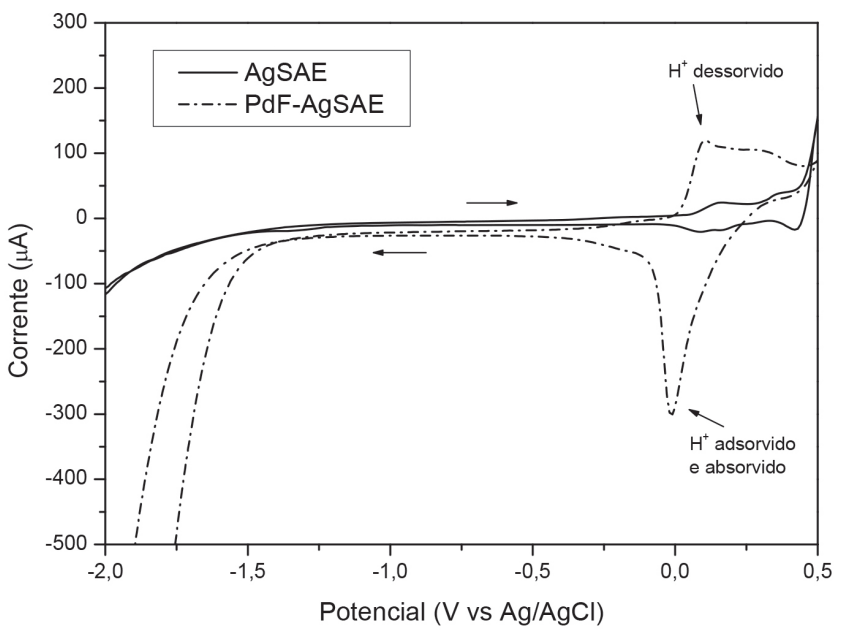

Figura 1. Comparação dos voltamogramas cíclicos da solução de $0,1 \mathrm{~mol} \mathrm{~L}^{-1}$ de $\mathrm{K}_{2} \mathrm{SO}_{4}, \mathrm{pH}$ 6,7, obtidos com os eletrodos AgSAE e PdF-AgSAE

Comparando a resposta do PdF-AgSAE com a resposta do AgSAE, para uma solução de $100 \mu \mathrm{g} \mathrm{L}^{-1}$ de $\mathrm{Tl}^{+}$em $0,1 \mathrm{~mol} \mathrm{~L}^{-1}$ $\mathrm{K}_{2} \mathrm{SO}_{4}$, observa-se que, nesse caso, o filme de paládio proporcionou um incremento de aproximadamente $150 \%$ na resposta do AgSAE (Figura 2). Verificou-se também a resposta do PdF-AgSAE e do AgSAE em uma solução de $1,0 \mathrm{mmol} \mathrm{L}^{-1} \mathrm{H}_{2} \mathrm{SO}_{4}$ contendo $100 \mu \mathrm{g} \mathrm{L}$ de $\mathrm{Tl}^{+}$. Nesse caso, obteve-se um incremento de $36 \%$ na resposta do eletrodo contendo o filme de paládio. Esse resultado sugere que a resposta do eletrodo de filme de paládio depende do pH da solução.

\section{Avaliação da deposição do filme de paládio no AgSAE}

$\mathrm{Na}$ deposição in situ, foram realizados estudos para verificar a influência da concentração de $\mathrm{Pd}^{2+}$ no sinal analítico do $\mathrm{Tl}^{+}$. Verificou-se que o aumento das concentrações de $\mathrm{Pd}^{2+}$ de $0,5 \mathrm{mg} \mathrm{L}^{-1}$ a $4,0 \mathrm{mg} \mathrm{L}^{-1}$ provocou aumento na corrente de pico do $\mathrm{Tl}^{+}$. Entretanto, nas soluções com concentrações de $\mathrm{Pd}^{2+}$ superiores a $4,0 \mathrm{mg} \mathrm{L}^{-1}$, foi observado desprendimento de gás, provavelmente gás hidrogênio, na superfície do eletrodo de trabalho, prejudicando as medidas eletroquímicas.

Na deposição ex situ, empregando-se uma solução de $20,0 \mathrm{mg} \mathrm{L}^{-1}$ de $\mathrm{Pd}^{2+}$, foi avaliada a influência do tempo de deposição na formação do filme de paládio. Neste estudo, foi aplicado um potencial de deposição constante de -1,2 V, variando-se os tempos de deposição em $60,120,180,240,300,360$ e 420 s. Observou-se que, ao aplicar um potencial de $-1,2 \mathrm{~V}$ durante $60 \mathrm{~s}$, a superfície do AgSAE, inicialmente com aspecto espelhado, exibia coloração marrom claro 


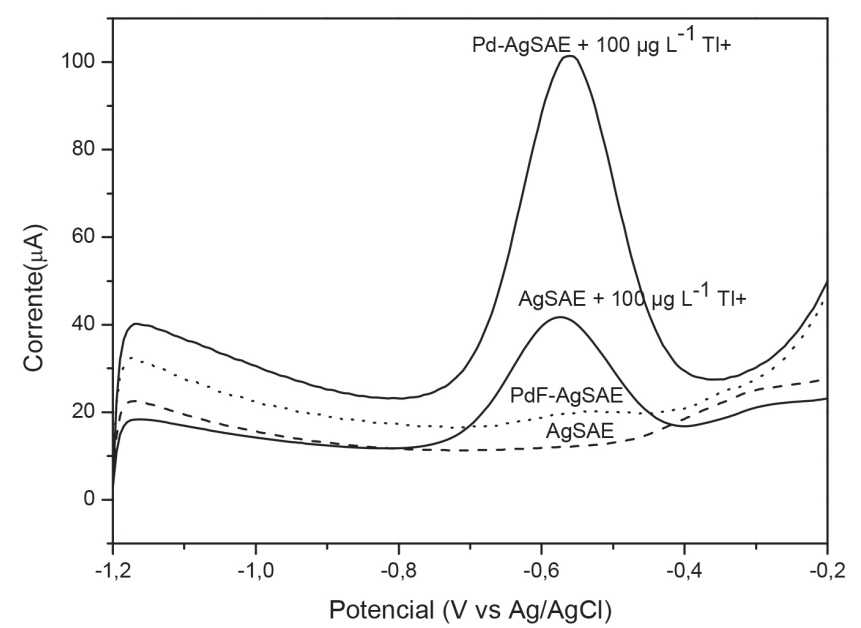

Figura 2. Voltamogramas de uma solução de $100 \mu \mathrm{g} \mathrm{L}^{-1} \mathrm{Tl}^{+}$em $0,1 \mathrm{~mol} \mathrm{~L} \mathrm{~L}^{-1}$ de $\mathrm{K}_{2} \mathrm{SO}_{4}$ ( $\mathrm{pH}$ 6,7), obtidos por voltametria de redissolução anódica com pulso diferencial empregando os eletrodos AgSAE sem filme de paládio e com o filme de paládio PdF-AgSAE (depositado ex situ, potential de deposição de -1,2 V em 300s). Voltamogramas obtidos com os eletrodos, AgSAE (- - -) e

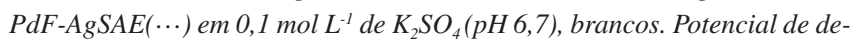
posição-1,2 V, tempo de deposição 300 s, tempo de equilíbrio 20s, velocidade de varredura $80 \mathrm{mV} \mathrm{s}^{-1}$, pulso de $50 \mathrm{mV}$, tempo de pulso $10 \mathrm{~ms}$

não homogêneo na superfície do eletrodo. Nos tempos de deposição de 120,180 e 240 s, verificou-se a formação de um filme negro de paládio (paládio finamente dividido), porém, a superfície do eletrodo não foi totalmente recoberta. Já no tempo de 300 s houve a formação do filme negro de paládio homogêneo recobrindo toda a superfície do eletrodo (Figura 1S, material suplementar). Em tempos superiores, o filme formado revelou aspecto não homogêneo. Desse modo, o tempo de deposição selecionado neste trabalho foi de $300 \mathrm{~s}$.

$\mathrm{Na}$ avaliação da reprodutibilidade do filme de paládio, depositado ex situ, foram realizadas medidas $(\mathrm{n}=10)$ em solução contendo $100 \mu \mathrm{g}$ $\mathrm{L}^{-1} \mathrm{de} \mathrm{Tl}^{+}$, utilizando três eletrodos com filmes de Pd, depositados sob a mesma condição. Considerando todas as medidas $(n=30)$ realizadas com os três filmes, o coeficiente de variação (RSD) encontrado foi menor que $2,0 \%$, demostrando a boa reprodutibilidade no procedimento de deposição do filme.

Nas condições estabelecidas, comparando as correntes de pico do $\mathrm{Tl}^{+}$obtidas com os filmes de paládio depositados in situ e ex situ, constatou-se que não houve diferença significativa entre as intensidades das correntes de pico obtidas em ambos os filmes. Sendo assim, nesse trabalho, optou-se pela utilização do filme de paládio depositado ex situ, devido à possibilidade do uso de um único filme em várias determinações.

\section{Caracterização da superficíe do eletrodo de filme de paládio}

$\mathrm{Na}$ análise química semi quantitativa da superfície do AgSAE por Espectroscopia de Energia Dispersiva (EDS, Energy-Dispersive $X$-ray Spectroscopy) a proporção em massa encontrada para o Ag e para o $\mathrm{Hg}$ foi de 33/67 (Ag/Hg; m/m), concordando com os percentuais utilizados na preparação da amálgama de prata. Os resultados da análise da superfície do filmes de paládio por EDS, revelaram percentuais em massa para os elementos $\mathrm{Pd}, \mathrm{Hg}$ e $\mathrm{Ag}$ de $80,06 \%$, $12,83 \%$ e $7,12 \%$, respectivamente. O percentual encontrado para o $\mathrm{Pd}$ pode ser um indicativo de que nem toda a superfície do AgSAE foi recoberta pelo filme de paládio.

Um dos parâmetros mais importantes na caracterização da superfície dos eletrodos sólidos é a determinação da área superficial ativa. Diferentemente dos eletrodos de mercúrio e de amalgama de prata, ${ }^{45}$ nos eletrodos sólidos de metais nobres (e.g Pd, Pt, Au, Rh e etc) a área da superfície eletroativa pode assumir valores 1000 vezes maiores que a sua área geométrica. ${ }^{46,47} \mathrm{O}$ tamanho da área ativa do eletrodo tem relação direta com a rugosidade da sua superfície e o aumento, por exemplo, da deposição de um filme condutor poroso, resultando assim no aumento da sensibilidade e, consequentemente, na diminuição do limite de detecção do método. ${ }^{48-50}$

A determinação da área superficial ativa do filme de paládio foi realizada, pela estimativa da carga envolvida na redução de uma monocamada de PdO formada na superfície do eletrodo empregado na técnica de voltametria cíclica. Este método é comumente empregado na determinação eletroquímica da área superficial ativa em eletrodos de paládio. ${ }^{42,46,51,52}$

Nesta abordagem, a monocamada de $\mathrm{PdO}$ é formada no potencial limite anódico de $1,4 \mathrm{~V}$ e assume-se o valor de $424 \mu \mathrm{C} \mathrm{cm}^{-2}$ como a densidade de carga associada com a redução desta monocamada. Os voltamogramas cíclicos foram obtidos realizando a varredura numa solução de $\mathrm{H}_{2} \mathrm{SO}_{4} 0,5 \mathrm{~mol} \mathrm{~L}^{-1}$ contendo oxigênio atmosférico dissolvido e o valor da carga envolvida na redução da monocamada de $\mathrm{PdO}$ foi encontrado pela integração da área do pico catódico conforme a equação abaixo: ${ }^{42,46,51,52}$

$$
Q=\frac{1}{v} \int_{E 1}^{E 2} I d E
$$

sendo $\mathrm{V}$ a velocidade de varredura na voltametria cíclica, I a corrente no intervalo de potencial $\left(\mathrm{E}_{1}\right.$ a $\left.\mathrm{E}_{2}\right)$ correspondente ao pico de redução do $\mathrm{PdO}$.

Conforme apresentado na Figura 3 A, no voltamograma cíclico obtido para uma solução de $\mathrm{H}_{2} \mathrm{SO}_{4} 0,5 \mathrm{~mol} \mathrm{~L}^{-1}$ empregando-se o eletrodo de filme de paládio, observa-se no potencial de $0,3 \mathrm{~V}$ um pico catódico correspondente a redução da monocamada de PdO. A partir da integração da área do pico catódico, o valor encontrado para carga correspondente a redução da monocamada de $\mathrm{PdO}$ foi de 39,68 $\mathrm{mC}(39680 \mu \mathrm{C})$ e a área superficial ativa $\left(\mathrm{S}_{\mathrm{a}}\right)$ do filme de paládio foi estimada em 93,6 cm² ( $\left.\mathrm{S}_{\mathrm{a}}=39680 \mu \mathrm{C} / 424 \mu \mathrm{C} \mathrm{cm} \mathrm{cm}^{-2}\right)$.

A grande área superficial ativa em relação a área geométrica $\left(\mathrm{Sg}=0,03 \mathrm{~cm}^{2}\right)$ indica que o filme de paládio possui uma estrutura bastante porosa. A formação da porosidade no filme de paládio pode estar associada ao fato do paládio ter sido depositado em potencial catódico $(-1,2 \mathrm{~V})$ no qual houve a redução do hidrogênio e desprendimento de gás na superfície do eletrodo. ${ }^{53}$ Segundo Li et al.,${ }^{54} \mathrm{em}$ filmes metálicos depositados em potenciais catódicos onde ocorre a redução do hidrogênio, as bolhas do gás funcionam como um molde dinâmico para eletrodeposição do metal. As estruturas resultantes são filmes metálicos com alta porosidade e grande superfície ativa.

As características morfológicas da superfície do filme de paládio foram avaliadas através da Microscopia Eletrônica de Varredura (MEV). Na Figura 3B são apresentadas as micrografias da superfície do PdF-AgSAE, podendo ser confirmada a porosidade do filme de paládio. A avaliação da topografia da superfície do filme de paládio foi realizada pelas imagens (Figura $2 \mathrm{~S}$ e Figura 3S, material suplementar) obtidas por Microscopia de Força Atômica (AFM, acrônimo do inglês Atomic Force Microscopy). A partir da secção (P-Q) da imagem topográfica (Figura 4S, material suplementar), foi encontrado um valor $65 \mathrm{~nm}$ para rugosidade média $\left(\mathrm{R}_{\mathrm{a}}\right)$, demonstrando uma boa regularidade textural do filme de paládio.

\section{Efeito da composição do eletrólito suporte na resposta do eletrodo de filme de paládio}

Neste trabalho também foi investigado o desempenho do PdFAgSAE na detecção do $\mathrm{Tl}^{+}$em diferentes eletrólitos suporte. Foram investigados individulamente os eletrólitos ácidos, $\mathrm{HCl}, \mathrm{HNO}_{3} \mathrm{e}$ 

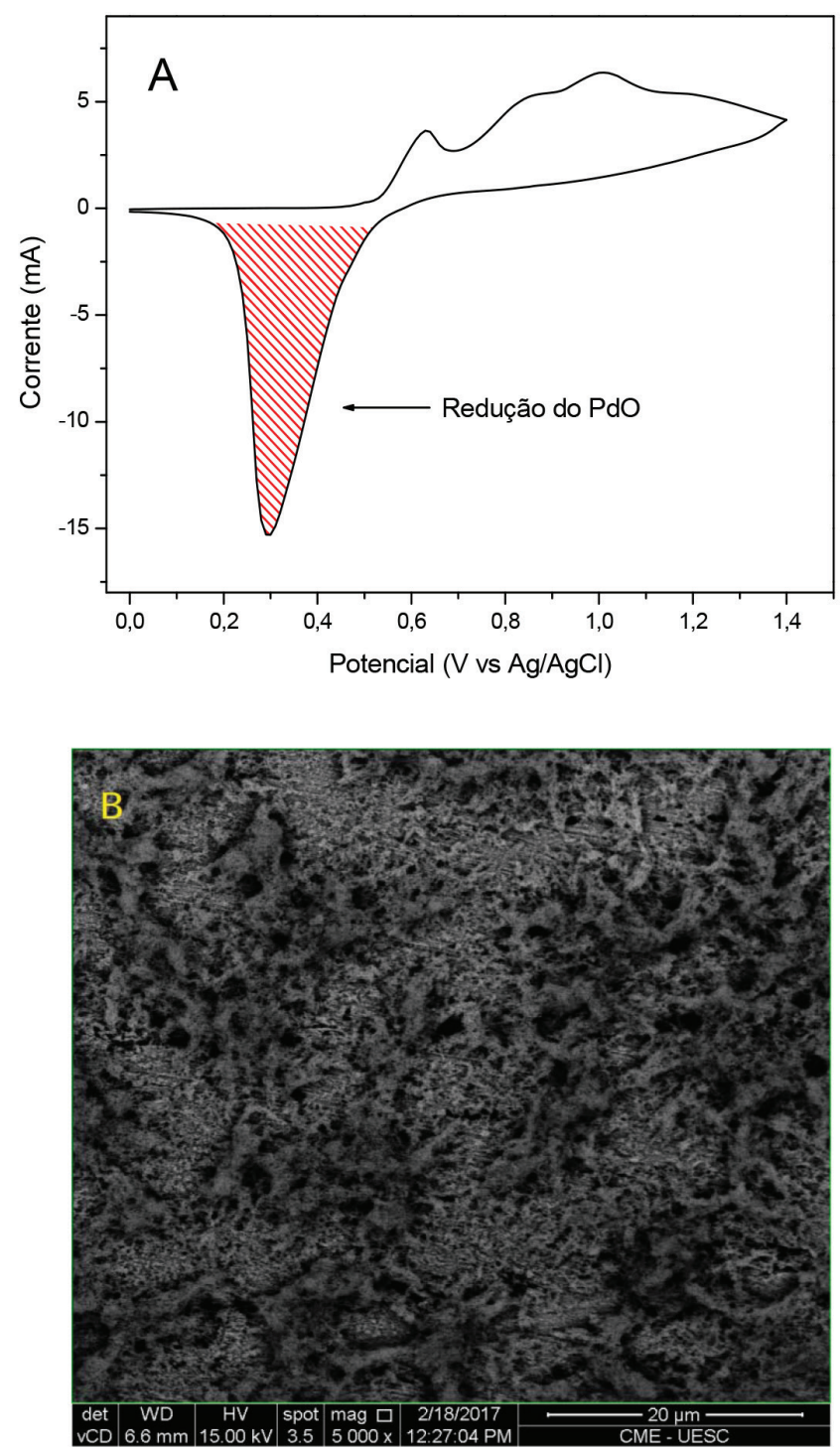

Figura 3. A) Voltamograma cíclico do filme de paládio para uma solução de $\mathrm{H}_{2} \mathrm{SO}_{4} 0,5 \mathrm{~mol} \mathrm{~L}^{-1}$ em velocidade de varredura de potencial de $50 \mathrm{mV} \mathrm{s}^{-1}$. A área hachurada em vermelho foi utilizada na estimativa da carga total envolvida no processo de redução da monocamada de PdO. B)Micrografias da superfície do PdF-AgSAE ampliada 5000X (B)

$\mathrm{H}_{2} \mathrm{SO}_{4}$, na concentração de $1,0 \mathrm{mmol} \mathrm{L} \mathrm{L}^{-1} \mathrm{e}$, os eletrólitos salinos, $\mathrm{KCl}, \mathrm{KNO}_{3}$ e $\mathrm{K}_{2} \mathrm{SO}_{4}$, na concentração de $0,1 \mathrm{~mol} \mathrm{~L}^{-1}$. Verificou-se que os sinais analíticos foram menores em eletrólitos ácidos do que em salinos, sugerindo que a atividade dos íons na superfície do PdFE é dependente do $\mathrm{pH}$ da solução. Em relação à composição dos eletrólitos, observou-se que o sinal analítico diminui na seguinte ordem dos ânions: $\mathrm{NO}_{3}{ }^{-}<\mathrm{SO}_{4}{ }^{2-}<\mathrm{Cl}^{-}$, sendo tal efeito mais pronunciado nos eletrólitos ácidos do que nos salinos. Esse resultado corrobora com dados da literatura, na qual é reportada que em soluções aquosas e ácidas, os ânions cloretos interagem mais fortemente com a superfície do eletrodo de paládio do que o sulfato e o nitrato, respectivamente. ${ }^{42}$

\section{Efeito do pH na resposta do eletrodo}

O estudo do efeito do $\mathrm{pH}$ entre 4,0 a 10,0 sobre resposta do eletrodo foi realizado utilizando soluções de $100 \mu \mathrm{g} \mathrm{L}^{-1} \mathrm{deTl}^{+}$em 0,1 mol L-1 $\mathrm{K}_{2} \mathrm{SO}_{4}$, ajustado o $\mathrm{pH}$ com a adição de solução de $1,0 \mathrm{~mol}$ $\mathrm{L}^{-1} \mathrm{H}_{2} \mathrm{SO}_{4}$ e $1,0 \mathrm{~mol} \mathrm{~L}{ }^{-1}$ de $\mathrm{KOH}$. Na faixa de $\mathrm{pH}$ estudada, não foi observado deslocamento no valor do potencial da corrente de pico relativo ao $\mathrm{Tl}^{+}$, demonstrando que o potencial de redução desse íon não foi afetado pela variação de $\mathrm{pH}$ do meio.

A Figura 4 apresenta o perfil da variação na corrente de redução do $\mathrm{Tl}^{+}$com o $\mathrm{pH}$ do meio. A maior corrente foi obtida em $\mathrm{pH}$ 7, sendo que em valores de $\mathrm{pH}$ nferiores a 6 e superiores a 7, observa-se uma diminuição na corrente. Este comportamento provavelmente está associado a hidratação ou hidroxilação da superfície do filme de paládio, como relatado na literatura. ${ }^{55}$

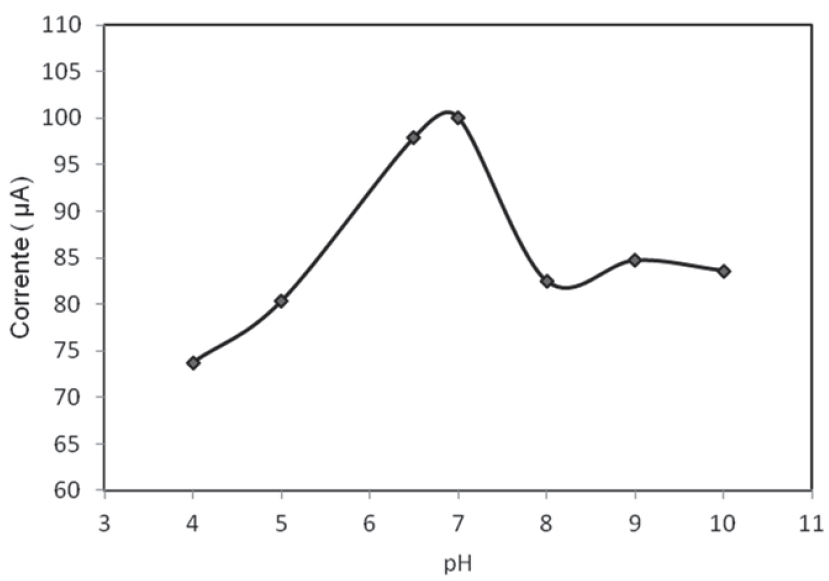

Figura 4. Influência do pH na magnitude da corrente de pico do $\mathrm{Tl}^{+}$

\section{Estudos dos interferentes na detecção do tálio}

Os principais interferentes na determinação de $\mathrm{Tl}^{+}$por técnicas voltamétricas são os íons $\mathrm{Cd}^{2+}, \mathrm{Pb}^{2+} \mathrm{e} \mathrm{Cu}^{2+}$, porque os dois primeiros possuem potenciais de redução próximos ao do $\mathrm{Tl}^{+}$e o $\mathrm{Cu}^{2+}$ pode formar espécies intermetálicas com o $\mathrm{Tl}^{+} .{ }^{56-60}$ Além disso, em amos-

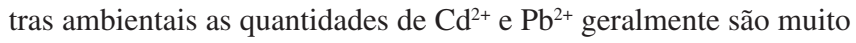
mais altas que a de $\mathrm{Tl}^{+}$.

Em procedimentos eletroquímicos, para determinação do $\mathrm{Tl}^{+}$, normalmente é utilizado EDTA em concentrações na ordem de $10^{-3} \mathrm{~mol} \mathrm{~L}^{-1} \mathrm{em} \mathrm{pH} \sim 4,0$ para contornar as interferências causadas principalmente pelo $\mathrm{Cd}^{2+} \mathrm{e} \mathrm{Pb}^{2+} .57,59,61-65$ Isso porque, o EDTA em meio moderadamente ácido, na faixa de $\mathrm{pH}$ entre 4-5, não forma complexo com o $\mathrm{Tl}^{+}$, mas forma complexo estáveis com o $\mathrm{Cd}^{2+} \mathrm{e}$ $\mathrm{Pb}^{2+}{ }^{63,66}$ Assim, neste trabalho optou-se utilizar EDTA na concentração de $0,001 \mathrm{~mol} \mathrm{~L}^{-1}$ em $0,1 \mathrm{~mol} \mathrm{~L}^{-1}$ de $\mathrm{K}_{2} \mathrm{SO}_{4} \mathrm{em} \mathrm{pH}=4,0$ por ser a condição mais apropriada para supressão desses interferentes.

Nas condições experimentais estabelecidas para esse trabalho, a presença dos íons $\mathrm{Cd}^{2+} \mathrm{e} \mathrm{Cu}^{2+}$ em concentrações 25 vezes superiores a do $\mathrm{Tl}^{+}$não provocou interferência no sinal analítico. Com relação ao $\mathrm{Pb}^{2+}$, foi observado que o EDTA não suprimiu o sinal analítico deste íon, quando presente numa concentração de até 10 vezes maior que a do $\mathrm{Tl}^{+}$. Entretanto, em $\mathrm{pH}=4,0 \mathrm{o} \mathrm{Pb}^{2+}$ não interferiu no sinal do $\mathrm{Tl}^{+}$, apresentando corrente de pico em potencial distinto. Assim, em amostras livre de $\mathrm{Cd}^{2+}$ e acidificada em $\mathrm{pH}=4,0$, foi possível a

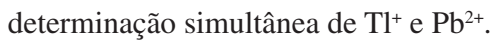

\section{Avaliação da estabilidade do filme de paládio depositado ex situ}

Na avaliação da estabilidade do filme de paládio depositado ex situ foram feitas 40 medidas sucessivas ${ }^{67-69} \mathrm{em}$ uma solução contendo $100 \mu \mathrm{g} \mathrm{L} \mathrm{de} \mathrm{Tl}^{+}$, 0,001 mol L-1 EDTA (pH=4,0) em 0,1 mol L $\mathrm{me}^{-1} \mathrm{de}$ $\mathrm{K}_{2} \mathrm{SO}_{4}$ como eletrólito suporte. As primeiras 20 medidas foram realizadas em um dia e as outras 20 medidas realizadas no dia seguinte.

A Figura 5 apresenta os valores da corrente de pico que foram obtidas na repetição das medidas ao longo de dois dias. $\mathrm{O}$ valor de $\operatorname{RSD}(\%)$ das medidas realizadas no $1^{\circ}$ dia foi menor $(1,49 \%)$, quando 
comparado com aquele obtido para o $2^{\circ}$ dia $(4,0 \%)$. Esses resultados demonstram que o filme de paládio oferece uma boa estabilidade até as primeiras 20 medidas e o seu uso é satisfatório, do ponto de vista analítico, até 40 determinações. Desse modo, recomenda-se que nos trabalhos que exijam precisão com RSD menor que $4 \%$, seja realizada recalibração do procedimento ou, uma nova deposição do filme de paládio, a cada 20 medidas.

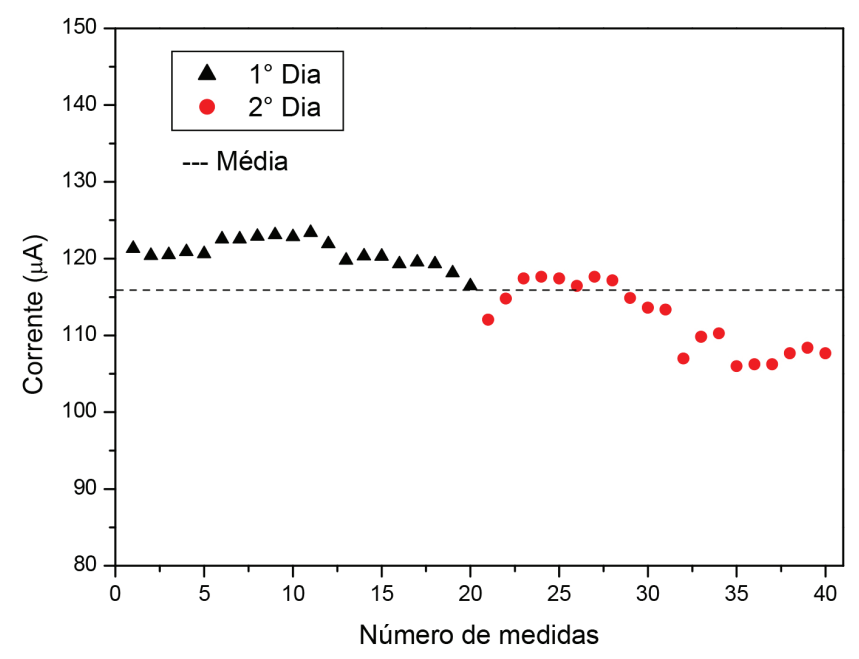

Figura 5. Valores da corrente de pico em medidas repetidas $(n=40)$ de uma soluçãol00 $\mu \mathrm{g} \mathrm{L}^{-1}$ de $\mathrm{Tl}^{+}$em 0,1 $\mathrm{mol} \mathrm{L}^{-1} \mathrm{~K}_{2} \mathrm{SO}_{4}$ contendo 0,001 mol $\mathrm{L}^{-1}$ de EDTA $(p H=4,0)$. ( $\mathbf{\Delta})$ Medidas realizadas no primeiro dia. (○) Medidas realizadas no dia seguinte

\section{Características analíticas do PdF-AgSAE na determinação de tálio por DPASV}

Na determinação do tálio por DPASV os parâmetros instrumentais utilizados foram: potencial de pré-concentração em -1,2 V, tempo de deposição em 300s, tempo de equilíbrio em 20 s, velocidade de varredura a $100 \mathrm{mV} \mathrm{s}^{-1}$, amplitude de pulso em $50 \mathrm{mV}$ e tempo de pulso em $10 \mathrm{~ms}$. Na etapa de condicionamento e limpeza do eletrodo, foi aplicado um potencial de $+0,2 \mathrm{~V}$ durante $30 \mathrm{~s}$.

Com as condições de trabalho estabelecidas e utilizando como eletrólito suporte uma solução de $0,1 \mathrm{~mol} \mathrm{~L}^{-1} \mathrm{~K}_{2} \mathrm{SO}_{4}$ contendo 0,001 mol L ${ }^{-1}$ EDTA em $\mathrm{pH}=4,0$, foram obtidos voltamogramas de pulso diferencial para soluções de tálio, sendo observados linearidade entre 3,0 a 100,0 $\mu \mathrm{g} \mathrm{L}^{-1}$ para o $\mathrm{Tl}^{+}$nas medidas das correntes de pico de redução (Ip) catódica. A inserção na Figura 6 apresenta os voltamogramas obtidos na DPASV para as diferentes concentrações de $\mathrm{Tl}^{+}$. Observa-se, nos voltamogramas um aumento da corrente de pico catódico, proporcional com a concentração de tálio estudada, sem deslocamento do potencial de pico.

Observa-se nos voltamogramas obtidos valores de corrente de fundo associados à redução do oxigênio dissolvido durante a varredura em potenciais negativos. Contudo, os teores de oxigênio dissolvido nas soluções de calibração foram mantidas constantes $\left(2,9 \mathrm{mg} \mathrm{L}^{-1}\right) \mathrm{e}$ a sua contribução na corrente de pico do $\mathrm{Tl}^{+}$foi, na curva analítica, devidamente corrigida.

Na Figura 6 é apresentada o perfil da curva analítica, sendo descrita pela equação Ip $(\mu \mathrm{A})=1,00\left[\mathrm{Tl}^{+}\left(\mu \mathrm{g} \mathrm{L}^{-1}\right)\right]+0,51$ e coeficiente de correlação linear $R=0,9997$. Os limites de detecção (LD) e de quantificação (LQ) foram estimados a partir dos desvios padrão do branco e o coeficiente angular da curva analítica, conforme as recomendações da IUPAC,,$^{70}$ e os valores encontrados foram $0,89 \mu \mathrm{g} \mathrm{L}^{-1}$ e $2,96 \mu \mathrm{g} \mathrm{L}^{-1}$, respectivamente.

A repetitividade do procedimento foi avaliada realizando

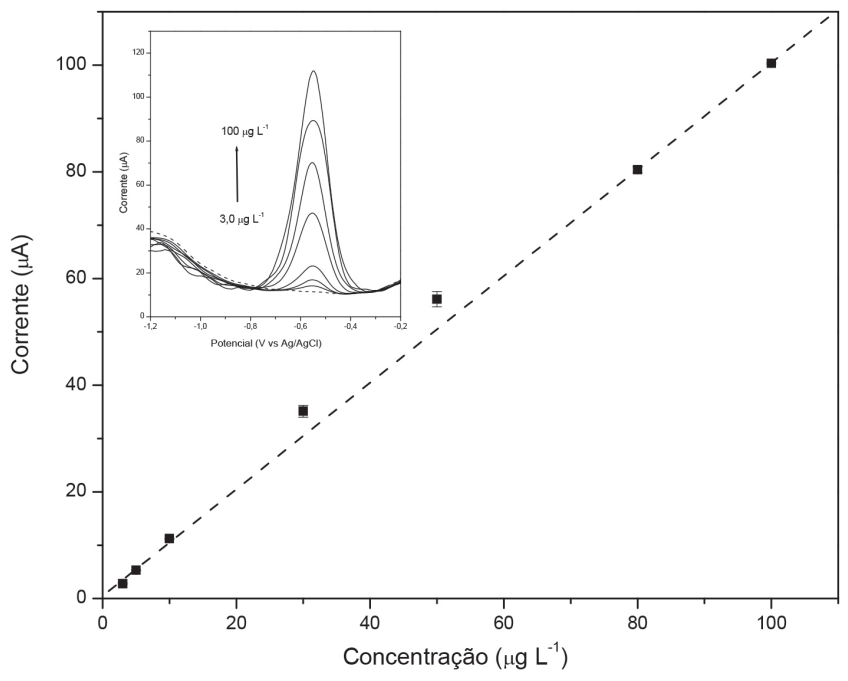

Figura 6. Curva analítica obtida a partir das correntes de pico correspon-

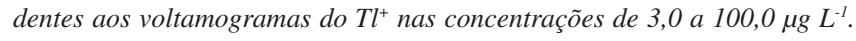
Potencial de pré-concentração -1,2 V, tempo de deposição $300 \mathrm{~s}$, tempo de equilíbrio $20 \mathrm{~s}$, varredura a $100 \mathrm{mV} \mathrm{s}^{-1}$, amplitude de pulso de $50 \mathrm{mV}$ e tempo de pulso em $10 \mathrm{~ms}$. Inserção: Voltamograma de pulso diferencial em diferentes concentrações de $\mathrm{Tl}^{+}$em 0,1 $\mathrm{mol} \mathrm{L}^{-1} \mathrm{~K}_{2} \mathrm{SO}_{4}, 0,001 \mathrm{~mol} \mathrm{~L}^{-1} \mathrm{EDTA}$ em pH 4,0

sucessivas medidas $(\mathrm{n}=10)$ de uma solução padrão de $\mathrm{Tl}^{+}$. Para as soluções contendo $\mathrm{Tl}^{+}$nas concentrações de 5,0; 20,0 e 100,0 $\mu \mathrm{g} \mathrm{L}^{-1}$ foram obtidos coeficientes de variação (RSD \%) de $0,53 \%, 0,79 \%$ e $1,95 \%$, respectivamente.

$\mathrm{Na}$ avaliação da exatidão do procedimento foi realizado estudo de adição e recuperação. Neste estudo, três concentrações de $\mathrm{Tl}^{+}$ (10,0 $\mu \mathrm{g} \mathrm{L}^{-1}, 50,0 \mu \mathrm{g} \mathrm{L}^{-1}$ e 100,0 $\left.\mu \mathrm{g} \mathrm{L}^{-1}\right)$ foram adicionadas em amostras de águas. Os resultados obtidos, descontados dos resultados encontrados originalmente na amostra sem adição de padrão, são apresentados na Tabela 1. Os valores encontrados na recuperação variaram de 101 a 109\%, sugerindo uma não significativa influência do efeito de matriz nas amostras sobre os resultados na determinação do $\mathrm{Tl}^{+}$.

Tabela 1. Estudo de adição e recuperação de $\mathrm{Tl}^{+} \mathrm{em}$ amostras de águas naturais

\begin{tabular}{lccc}
\hline Amostra & $\begin{array}{c}\text { Adicionado } \\
\left(\mu \mathrm{g} \mathrm{L}^{-1}\right)\end{array}$ & $\begin{array}{c}\text { Encontrado } \\
\left(\mu \mathrm{g} \mathrm{L}^{-1}\right)\end{array}$ & $\begin{array}{c}\text { Recuperação } \\
(\%)\end{array}$ \\
\hline \multirow{3}{*}{ Água natural } & 10 & $10,4 \pm 0,1$ & 104 \\
& 50 & $54,3 \pm 1,0$ & 109 \\
& 100 & $100,7 \pm 1,0$ & 101 \\
\hline
\end{tabular}

O desempenho analítico do procedimento proposto na determinação de $\mathrm{Tl}^{+}$foi comparado com o desempenho de outros métodos eletroanalíticos reportados na literatura, Tabela 2. De modo geral as figuras de mérito obtidos nesta proposta foram similares aquelas observadas nos demais trabalhos. O método proposto apresentou um limite de detecção similar aos apresentados por outros métodos voltamétricos, sendo superior em alguns casos. Além disso, o método proposto também demonstrou uma melhor precisão em relação aos outros métodos. Apesar do método apresentado por Lee et al. ${ }^{56}$ apresentar um limite de detecção (LD) menor do que o método proposto, esses autores utilizaram um tempo de pré-concentração de 600 s, o dobro do tempo utilizado no protocolo de análise desta proposta (300s). O método apresentado por Spano et al. ${ }^{57}$ também possui um menor limite de detecção, porém o método proposto possui uma melhor precisão. 
Tabela 2. Características analíticas do método proposto na determinação de $\mathrm{Tl}^{+}$em comparação com alguns métodos eletroanalíticos reportados na literatura

\begin{tabular}{|c|c|c|c|c|c|c|c|}
\hline Ref. & Eletrodo & $\begin{array}{c}\text { Técnica } \\
\text { Voltamétrica }\end{array}$ & Matriz & $\begin{array}{l}\mathrm{T}^{*} \\
(\mathrm{~S})\end{array}$ & $\begin{array}{l}\text { Faixa Linear } \\
\left.\quad(\mu \mathrm{g} \mathrm{L})^{-1}\right)\end{array}$ & $\begin{array}{c}\mathrm{LD} \\
\left(\mu \mathrm{g} \mathrm{L}^{-1}\right)\end{array}$ & $\begin{array}{l}\mathrm{RSD} \\
(\%)\end{array}$ \\
\hline Nasiri-Majd et al. $(2015)^{8}$ & Polímero impresso com íon & DPASV & Água & 300 & $3-240$ & 0,76 & 2,7 \\
\hline Kokkinos et al. $(2014)^{71}$ & Filme de Sn & SWASV & Água & 240 & $0-80$ & 1,1 & 5,2 \\
\hline CheraghI et al. $(2013)^{72}$ & $\begin{array}{l}\text { Pasta de carbono modificado com éter } \\
\text { dicicloexil -[18] - coroa- } 6\end{array}$ & DPASV & Água & 300 & $3-250$ & 0,86 & 2,7 \\
\hline Lezi et al. $(2013)^{59}$ & $\begin{array}{l}\text { Eletrodos Impressos modificados com precur- } \\
\text { sores de bismuto }\end{array}$ & DPASV & Água & 120 & $5-40$ & $0,9-1,6$ & $6,0-9,1$ \\
\hline Lee et al. $(2008)^{56}$ & Grafite modificado com filme de bismuto & SWASV & Água & $\begin{array}{l}180^{\mathrm{a}} \\
600^{\mathrm{b}}\end{array}$ & $\begin{array}{c}1-10 \mathrm{e} \\
10-100\end{array}$ & $\begin{array}{c}0,03 \mathrm{e} \\
1,00\end{array}$ & - \\
\hline Dong et al. $(2006)^{73}$ & $\begin{array}{l}\text { Carbono vítreo modificado com filme de } \\
\text { p-allylcalix[4]arene }\end{array}$ & LV & Água & 150 & $5-250$ & 1,0 & 8,2 \\
\hline Spano et al. $(2005)^{57}$ & Microeletrodo de grafite & SWASV & Água & 300 & $5-350$ & 0,01 & $<9$ \\
\hline Método Proposto & Filme de Pd & DPASV & Água & 300 & $3-100$ & 0,89 & 1,95 \\
\hline
\end{tabular}

LD = limite de detecção; RSD= Desvio padrão relativo; DPASV=Voltametria de redissolução anódica com pulso diferencial, SWASV=Voltametria anódica com onda quadrada, LV= Voltametria de varredura linear; * Tempo de pré-concentração (s); ${ }^{\mathrm{a}}$ Tempo de pré-concentração usado no protocolo analítico; ${ }^{\mathrm{b}} \mathrm{Tempo}$ de pré-concentração, usado para obtenção do LD pelo método da relação sinal-ruído.

\section{Características analíticas do PdF-AgSAE na determinação simultânea de $\mathrm{Tl}^{+}$e $\mathrm{Pb}^{2+}$ por DPASV}

As medidas foram realizadas a uma velocidade de varredura de $100 \mathrm{mV} \mathrm{s}^{-1}$, tempo de pulso de $10 \mathrm{~ms}$ e amplitude de pulso de 50 $\mathrm{mV}$. Como eletrólito suporte foi utilizado $0,1 \mathrm{~mol} \mathrm{~L}^{-1} \mathrm{~K}_{2} \mathrm{SO}_{4} \mathrm{com} \mathrm{pH}$ ajustado para 4,0 através da adição da solução de $1,0 \mathrm{~mol} \mathrm{~L}^{-1} \mathrm{H}_{2} \mathrm{SO}_{4}$. Nessas condições de trabalho, foram obtidos voltamogramas das medidas feitas por DPASV nas soluções padrões contendo $\mathrm{Tl}^{+} \mathrm{e} \mathrm{Pb}^{2+}$ em diferentes concentrações (Figura 7). Na determinação simultânea

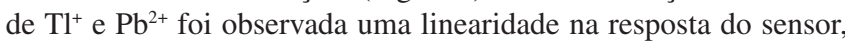
correntes de pico $(\mathrm{Ip} / \mu \mathrm{A})$, na faixa entre 5,0 a $80,0 \mu \mathrm{g} \mathrm{\textrm {L } ^ { - 1 }}$.

As curvas analíticas foram obtidas pela medida em triplicata de soluções contendo $\mathrm{Tl}^{+}$e $\mathrm{Pb}^{2+}$ na faixa de concentração de 5,0 a $80,0 \mu \mathrm{g} \mathrm{L}^{-1}$ (Inserção da Figura 7). Os sinais analíticos foram corrigidos frente a contribuição da corrente de fundo do oxigênio, e o comportamento linear para o $\mathrm{Pb}^{2+}$ é descrito pela equação Ip $(\mu \mathrm{A})=2,69\left[\mathrm{~Pb}^{2+}\left(\mu \mathrm{g} \mathrm{L} \mathrm{L}^{-1}\right)\right]+0,04$ e coeficiente de correlação linear de $\mathrm{R}=0,9919$. Para o $\mathrm{Tl}^{+}$os parâmetros da equação são: Ip $(\mu \mathrm{A})=1,50\left[\mathrm{Tl}^{+}\left(\mu \mathrm{g} \mathrm{L^{-1 }}\right)\right]-0,02$, com coeficiente de correlação linear de $\mathrm{R}=0,9999$. Os valores de $\mathrm{LD}$ e $\mathrm{LQ}$ estimados para o $\mathrm{Pb}^{2+}$ foram de $0,91 \mu \mathrm{g} \mathrm{L} \mathrm{L}^{-1}$ e 3,04 $\mu \mathrm{g} \mathrm{L}^{-1}$, respectivamente e, para o $\mathrm{Tl}^{+}$de $1,21 \mu \mathrm{g} \mathrm{L} \mathrm{L}^{-1} \mathrm{e} 4,00 \mu \mathrm{g} \mathrm{L} \mathrm{-}^{-1}$, respectivamente.

A repetitividade do procedimento para determinação simultânea de $\mathrm{Tl}^{+}$e $\mathrm{Pb}^{2+}$ foi avaliada pelas medidas sucessivas $(\mathrm{n}=10)$ de uma solução padrão contendo ambos os íons. Para as soluções contendo $\mathrm{Tl}^{+}$e $\mathrm{Pb}^{2+}$ nas concentrações de 10,$0 ; 50,0$ e 80,0 $\mu \mathrm{g} \mathrm{L}^{-1}$, os coeficientes de variação (RSD \%) obtidos foram menores que $2,0 \%$ em todos os casos.

$\mathrm{Na}$ avaliação da exatidão do procedimento, soluções padrões de $\mathrm{Tl}^{+}$e $\mathrm{Pb}^{2+}$ nas concentrações de $10 \mu \mathrm{g} \mathrm{L}^{-1}, 50 \mu \mathrm{g} \mathrm{L}^{-1}$ e $80 \mu \mathrm{g} \mathrm{L}^{-1}$, respectivamente, foram adicionados em amostras de água coletadas no Rio de Ondas, Barreiras-Ba. Os resultados obtidos são apresentados na Tabela 3 .

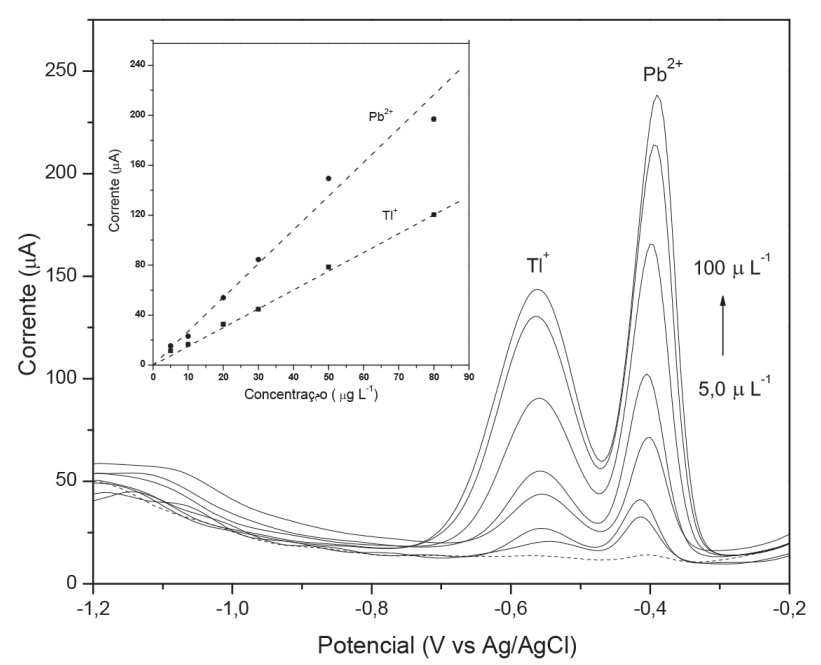

Figura 7. Voltamograma de pulso diferencial em diferentes concentrações

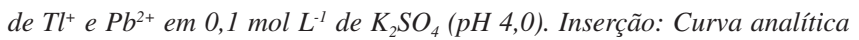
obtida a partir das correntes de pico correspondentes aos voltamogramas do

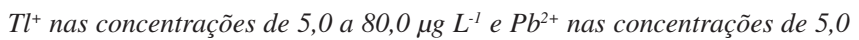
a $80 \mu \mathrm{g} \mathrm{L} \mathrm{L}^{-1}$. Potencial de pré-concentração $-1,2 \mathrm{~V}$, tempo de deposição 300 $\mathrm{s}$, tempo de equilíbrio $20 \mathrm{~s}$, varredura $100 \mathrm{mV} \mathrm{s}^{-1}$, amplitude de pulso $50 \mathrm{mV}$ e tempo de pulso de $10 \mathrm{~ms}$

\section{Aplicação analítica do PdF-AgSAE na determinação de tálio e chumbo em amostras de águas naturais}

O método proposto foi aplicado na determinação de $\mathrm{Tl}^{+} \mathrm{e} \mathrm{Pb}^{2+} \mathrm{em}$ amostras de água coletadas no Rio de Ondas, Oeste da Bahia, Brasil . As análises foram feitas em triplicatas e os resultados obtidos com o método proposto foram comparados com aqueles obtidos empregando o método USEPA $7010^{74}$ (da United State Environmental Protect Agency), utilizado como método de referência.

Tabela 3. Estudos de adição e recuperação na determinação simultânea de $\mathrm{Tl}^{+}$e $\mathrm{Pb}^{2+}$ em amostras de águas naturais

\begin{tabular}{|c|c|c|c|c|}
\hline \multirow{2}{*}{ Adicionado $\left(\mu \mathrm{g} \mathrm{L}^{-1}\right)$} & \multicolumn{2}{|c|}{$\mathrm{Tl}^{+}$} & \multicolumn{2}{|c|}{$\mathrm{Pb}^{2+}$} \\
\hline & Encontrado $\left(\mu \mathrm{g} \mathrm{L}^{-1}\right)$ & Recuperação (\%) & Encontrado $\left(\mu \mathrm{g} \mathrm{L}^{-1}\right)$ & Recuperação (\%) \\
\hline 10 & $11,07 \pm 0,34$ & 110,75 & $8,56 \pm 0,25$ & 85,60 \\
\hline 50 & $52,37 \pm 1,15$ & 104,74 & $54,64 \pm 0,32$ & 109,28 \\
\hline 80 & $80,46 \pm 0,46$ & 100,58 & $73,44 \pm 0,69$ & 91,81 \\
\hline
\end{tabular}


Em todas as amostras de água analisadas, as concentrações de $\mathrm{Tl}^{+} \mathrm{e} \mathrm{Pb}^{2+}$ apresentaram teores abaixo do limite de detecção do procedimento. Como as atividades de mineração do tálio na cidade de Barreiras-Ba ainda não foram iniciadas, isso pode justificar o fato de não ter sido detectado tálio nas amostras de água do Rio de Ondas. Além disso, esses resultados revelam que os processos naturais de intemperismo no minério de tálio não são suficientes para disponibilizar esse metal nas águas superficiais. Estudos complementares com relação a determinação destes elementos, com atenção especial ao tálio, em outras matrizes/compartimentos estão sendo realizados e serão posteriormente divulgados.

\section{CONCLUSÃO}

Nesse trabalho foi desenvolvido e caracterizado, um eletrodo de filme de paládio, preparado ex situ sobre amálgama de prata como substrato. O eletrodo apresentou adequado e similar desempenho, quando comparado a procedimentos eletroanalíticos reportados na literatura, além de boa estabilidade, podendo ser utilizado na determinação si-

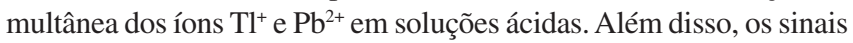
analíticos obtidos foram altamente reprodutíveis e muito bem definidos. Desse modo, o eletrodo de filme de paládio se mostrou promissor na determinação de metais pesados, podendo ser empregado nos casos em que os eletrodos de mercúrio não são convenientes. A priori ao nível de sensibilidade alcançado com o eletrodo, não foram detectados a

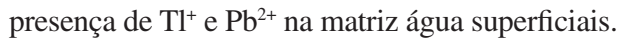

\section{MATERIAL SUPLEMENTAR}

No material suplementar, disponível gratuitamente em http:// quimicanova.sbq.org.br, na forma de PDF, estão apresentadas, a fotografia da superfície do eletrodo sólido de amálgama de prata AgSAE antes da deposição do filme de Pd e após deposição do filme de Pd (Figura 1S), bem como as imagens obtidas por AFM em 2D (Figura 2S) e em 3D (Figura 3S e Figura 4S) utilizadas na estimativa da rugosidade média do filme de Pd.

\section{AGRADECIMENTOS}

Os autores agradecem à Fundação de Amparo à Pesquisa do Estado da Bahia (PRONEX ÁGUA e PPP 049/2011), CNPq e CAPES, a Vagner Oliveira Santos do Laboratório de Microscopia Eletrônica LAMUME, do instituto de física da UFBA, ao Prof. Dr. Fábio Alan Carqueija Amorim da UESC, pelo apóio nas medidas realizadas com AFM, MEV e EDS, e ao Prof. Orlando Fatibello Filho, DQ UFSCar, pelos comentários e contribuições ao trabalho.

\section{REFERÊNCIAS}

1. Peter, A. L. J.; Viraraghavan, T.; Environ. Int. 2005, 31, 493.

2. Janoni, C. R.; Barbosa, J. S. F. A.; III Simpósio Brasileiro de Metalogenia, Gramado, Brasil, 2013.

3. Janoni, C. R.; Barbosa, J. S. F.; Cruz, S. C. P.; Souza, D. P. C.; XV Simpósio Nacional de Estudos Tectônicos, Vitória, Brasil, 2015.

4. Araujo, L. M.; Janoni, C. R.; Barbosa, J. S. F.; VII Simpósio Brasileira de Exploração Mineral, Ouro Preto, Brasil, 2016.

5. Galván-Arzate, S.; Santamaría, A.; Toxicol. Lett. 1998, 99, 1.

6. Fayazi, M.; Ghanei-Motlagh, M.; Taher, M. A.; Ghanei-Motlagh, R.; Salavati, M. R.; J. Hazard. Mater. 2016, 309, 27.

7. Pandey, G. P.; Singh, A. K.; Prasad, S.; Deshmukh, L.; Asthana, A.; Microchem. J. 2015, 118, 150.

8. Nasiri-Majd, M.; Taher, M. A.; Fazelirad, H.; Talanta 2015, 144, 204.
9. Das, A. K.; Dutta, M.; Cervera, M. L.; de la Guardia, M.; Microchem. J. 2007, 86, 2.

10. Das, A. K.; Chakraborty, R.; Cervera, M. L.; de la Guardia, M.; Anal. Bioanal. Chem. 2006, 385, 665.

11. Niu, X.; Lan, M.; Zhao, H.; Chen, C.; Li, Y.; Zhu, X.; Anal. Lett. 2013, 46, 2479.

12. Barón-Jaimez, J.; Joya, M. R.; Barba-Ortega, J.; J. Phys.: Conf. Ser. 2013, 466, 012007.

13. Aragay, G.; Pons, J.; Merkoçi, A.; Chem. Rev. 2011, 111, 3433.

14. Wang, J.; Analytical Electrochemistry, Wiley: New York, 2006.

15. Scholz, F.; Electroanalytical Methods: Guide to Experiments and Applications, Springer: Berlin, 2009.

16. Nunes, L. M. S.; Faria, R. C.; Electroanalysis 2008, 20, 2259.

17. Wang, J.; Lu, J.; Hocevar, S. B.; Farias, P. A. M.; Ogorevc, B.; Anal. Chem. 2000, 72, 3218.

18. Rehacek, V.; Hotovy, I.; Vojs, M.; Mika, F.; Microsyst. Technol. 2008, $14,491$.

19. Economou, A.; TrAC, Trends Anal. Chem. 2005, 24, 334.

20. Tesarova, E.; Baldrianova, L.; Hocevar, S. B.; Svancara, I.; Vytras, K.; Ogorevc, B.; Electrochim. Acta 2009, 54, 1506.

21. Hocevar, S. B.; Švancara, I.; Ogorevc, B.; Vytras, K.; Anal. Chem. 2007, $79,8639$.

22. Zhu, W. W.; Li, N. B.; Luo, H. Q.; Talanta 2007, 72, 1733.

23. Sebez, B.; Ogorevc, B.; Hocevar, S. B.; Veber, M.; Anal. Chim. Acta 2013, 785, 43 .

24. Sosa, V.; Barceló, C.; Serrano, N.; Ariño, C.; Díaz-Cruz, J. M.; Esteban, M.; Anal. Chim. Acta 2015, 855, 34.

25. Umemura, T.; Sato, K.; Kusaka, Y.; Satoh, H.; Handbook on the Toxicology of Metals, Elsevier: Amsterdam, 2015.

26. Bolza, A. E.; J. Electroanal. Chem. 1995, 380, 127.

27. Wang, X.; Wu, M.; Tang, W.; Zhu, Y.; Wang, L.; Wang, Q.; He, P.; Fang, Y.; J. Electroanal. Chem. 2013, 695, 10.

28. Ensafi, A. A.; Ahmadi, N.; Rezaei, B.; Abarghoui, M. M.; Talanta 2015, 134,745

29. Mukdasai, S.; Crowley, U.; Pravda, M.; He, X.; Nesterenko, E. P.; Nesterenko, P. N.; Paull, B.; Srijaranai, S.; Glennon, J. D.; Moore, E.; Sens. Actuators, B 2015, 218, 280.

30. Pham, X.-H.; Li, C. A.; Han, K. N.; Huynh-Nguyen, B.-C.; Le, T.-H.; Ko, E.; Kim, J. H.; Seong, G. H.; Sens. Actuators, B 2014, 193, 815.

31. Shao, M.; Xing, X.; Liu, C.; Electroanalysis 1994, 6, 245.

32. Mallát, T.; Petró, J.; Appl. Catal. 1990, 57, 71.

33. Mallát, T.; Bodnár, Z.; Szabó, S.; Petró, J.; Appl. Catal. 1991, 69, 85.

34. Scaros, M. G.; Prunier, M. L.; Catalysis of Organic Reactions; CRC Press: Boca Raton, 1994.

35. Tatsi, K.; Turner, A.; Sci. Total Environ. 2014, 473, 139.

36. Santos, J. L. O.; Santos, A. M. P.; de Jesus, D. S.; Leite, O. D.; $38^{a}$ Reunião Anual da Sociedade Brasileira de Química, Águas de Lindóia, Brasil, 2015.

37. Tian, Y.; Hu, L.; Han, S.; Yuan, Y.; Wang, J.; Xu, G.; Anal. Chim. Acta 2012, 738, 41.

38. Yosypchuk, B.; Barek, J.; Crit. Rev. Anal. Chem. 2009, 39, 189.

39. Yosypchuk, B.; Novotný, L.; Crit. Rev. Anal. Chem. 2002, 32, 141.

40. de Souza, D.; Melo, L. C.; Correia, A. N.; de Lima-Neto, P.; FatibelloFilho, O.; Mascaro, L. H.; Quim. Nova 2011, 34, 487.

41. Gabrielli, C.; Grand, P. P.; Lasia, A.; Perrot, H.; J. Electrochem. Soc. 2004, 151, A1937.

42. Grdeń, M.; Łukaszewski, M.; Jerkiewicz, G.; Czerwiński, A.; Electrochim. Acta 2008, 53, 7583.

43. Sheridan, L. B.; Kim, Y.-G.; Perdue, B. R.; Jagannathan, K.; Stickney, J. L.; Robinson, D. B.; J. Phys. Chem. C 2013, 117, 15728.

44. Tateishi, N.; Yahikozawa, K.; Nishimura, K.; Suzuki, M.; Iwanaga, Y.; Watanabe, M.; Enami, E.; Matsuda, Y.; Takasu, Y.; Electrochim. Acta 1991, 36, 1235 . 
45. Souza, D. De; Mascaro, L. H.; Fatibello-Filho, O.; J. Solid State Electrochem. 2011, 15, 2023.

46. Łukaszewski, M.; Soszko, M.; Czerwiński, A.; Int. J. Electrochem. Sci 2016, 11, 4442.

47. Beden, B.; Lamy, C.; De Tacconi, N. R.; Arvia, A. J.; Electrochim. Acta 1990, 35, 691.

48. Urbanová, V.; Bartoš, M.; Vytřas, K.; Kuhn, A.; Electroanalysis 2010, $22,1524$.

49. Urbanová, V.; Vytřas, K.; Kuhn, A.; Electrochem. Commun. 2010, 12, 114.

50. Jarzabek, G.; Borkowska, Z.; Electrochim. Acta 1997, 42, 2915.

51. Correia, A. N.; Mascaro, L. H.; Machado, S. A. S.; Avaca, L. A.; Electrochim. Acta 1997, 42, 493.

52. Fang, L.; Tao, Q.; Li, M.; Liao, L.; Chen, D.; Chen, Y.; Chin. J. Chem. Phys. 2010, 23, 543.

53. Zach, M. P.; Penner, R. M.; Adv. Mater. 2000, 12, 878.

54. Li, Y.; Song, Y.-Y.; Yang, C.; Xia, X.-H.; Electrochem. Commun. 2007, 9, 981.

55. Singh, V. V.; Nigam, A. K.; Boopathi, M.; Pandey, P.; Ganesan, K.; Jain, R.; Singh, B.; Vijayaraghavan, R.; Sens. Actuators, B 2011, 160, 840.

56. Lee, G.-J.; Lee, H. M.; Uhm, Y. R.; Lee, M. K.; Rhee, C.-K.; Electrochem. Commun. 2008, 10, 1920.

57. Spano, N.; Panzanelli, A.; Piu, P. C.; Pilo, M. I.; Sanna, G.; Seeber, R.; Tapparo, A.; Anal. Chim. Acta 2005, 553, 201.

58. Lukaszewski, Z.; Zembrzuski, W.; Talanta 1992, 39, 221.

59. Lezi, N.; Kokkinos, C.; Economou, A.; Prodromidis, M. I.; Sens. Actuators, B 2013, 182, 718.
60. Bonelli, J. E.; Taylor, H. E.; Skogerboe, R. K.; Anal. Chim. Acta 1980, $118,243$.

61. Calderoni, G.; Talanta 1982, 29, 371.

62. Ciszewski, A.; Łukaszewski, Z.; Talanta 1985, 32, 1101.

63. Vandenbalck, J. L.; Patriarche, G. J.; Sci. Total Environ. 1987, 60, 97.

64. Ciszewski, A.; Lukaszewski, Z.; Talanta 1988, 35, 191.

65. Jakubowska, M.; Zembrzuski, W.; Lukaszewski, Z.; Electroanalysis 2008, 20, 1073.

66. Temmerman, E.; Verbeek, F.; J. Electroanal. Chem. Interfacial Electrochem. 1968, 19, 423.

67. Nigović, B.; Šimunić, B.; Hocevar, S.; Electrochim. Acta 2009, 54, 5678.

68. Kefala, G.; Economou, A.; Voulgaropoulos, A.; Analyst 2004, 129, 1082.

69. Wang, J.; Prakash Deo, R.; Thongngamdee, S.; Ogorevc, B.; Electroanalysis 2001, 13, 1153.

70. Thompson, M.; Ellison, S. L. R.; Wood, R.; Pure Appl. Chem. 2002, 74, 835.

71. Kokkinos, C.; Economou, A.; Talanta 2014, 125, 215.

72. Cheraghi, S.; Taher, M. A.; Fazelirad, H.; Microchim. Acta 2013, 180, 1157.

73. Dong, H.; Zheng, H.; Lin, L.; Ye, B.; Sens. Actuators, B 2006, 115, 303.

74. United State Environmental Protection Agency; Method 7010, Graphite Furnace Atomic Absorption Spectrophotometry, disponível em https:// www.epa.gov/sites/production/files/2015-07/documents/epa-7010.pdf, acessado em Junho 2017. 